\title{
CONTAGEM BACTERIANA TOTAL EM AMOSTRAS DE LEITE DE TANQUE NO ESTADO DO PARANÁ
}

(Total bacterial count in milk samples from bulk tank Paraná State)

Newton Pohl Ribas ${ }^{1}$, José Augusto Horst, Uriel Vinicius Cotarelli de Andrade, Andressa

Regonato, Hendyel Aparecida Pacheco, Kamila Chaves Sermann

${ }^{1}$ Correspondência: newtonribas.ufpr@gmail.com

RESUMO: Avaliou-se os efeitos de meio sobre a contagem bacteriana total (CBT) e logarítmico da contagem bacteriana total (logCBT) de amostras de tanque individuais, comunitário e latões coletadas pelas indústrias, analisadas pelo Laboratório da Qualidade do Leite (LQL) da Associação Paranaense dos Criadores de Bovinos da Raça Holandesa (APCBRH) - Curitiba, PR. Foram analisadas 680.102 amostras de leite no período de janeiro de 2012 a maio de 2014 em dez regiões. As médias estimadas, desvios-padrão e coeficiente de variação para CBT, logCBT e idade da amostra foram: 1.307.000 \pm 1.859 .000 (UFC/mL), 136,7\%; 5,89 $\pm 1,93\left(\log _{10} \mathrm{UFCxmL}^{-1}\right), 29,5 \%$ e 2,95 $\pm 1,48$ dias, respectivamente. Os efeitos incluídos no modelo matemático influenciaram significativamente $(P<0,01)$ as variáveis estudadas. Menores valores para logCBT ocorreram no final do inverno e primavera (variando de 5,36 e 5,47 $\left(\log _{10} \mathrm{UFCxmL}{ }^{-1}\right)$ ). Com o passar dos anos, observou-se uma diminuição dos valores, (5,66 para 5,51 $\left.\left(\log _{10} \mathrm{UFCxmL} \mathrm{L}^{-1}\right)\right)$. A região influenciou significativamente o $\log C B T(\mathrm{P}<0,01)$, registrando a menor média de 3,64 em Campo Mourão e a maior de 6,44 ( $\log _{10} \mathrm{UFCxmL}^{-1}$ ) na Metropolitana de Curitiba, justificadas por diferentes níveis de tecnologias adotadas nas diferentes regiões. O Escore da Contagem de Células Somáticas (ECS) influenciou significativamente $(P<0,01)$ a CBT e o logCBT. Quando a idade da amostra variou de zero a dois dias o $\log C B T$ aumentou de 5,46 para 5,66 $\left(\log _{10}\right.$ UFC $\left.\times \mathrm{mL}^{-1}\right)$ e de três para sete dias, diminuíram de 5,66 para 5,57 ( $\log _{10}$ UFC $\left.\times \mathrm{mL}^{-1}\right)$. Resultados evidenciam a necessidade pelos produtores, técnicos e indústrias de reavaliarem seus procedimentos de higiene dos equipamentos de ordenha, resfriamento, temperatura e tempo de armazenagem do leite, melhorando a qualidade microbiológica do leite.

Palavras-chave: ano de análise; escore da contagem de células somáticas; idade da amostra; mês de análise; região de análise

ABSTRACT:. The effects of environment on total bacterial count (TBC) and logarithmic of total bacterial count (logCBT) of individual tank samples, community and cans collected by industries, analyzed by the Milk Quality Laboratory (LQL) the Paranaense Association Cattle breeders of Holstein (APCBRH) - Curitiba, PR were evaluated. Were analyzed 680102 milk samples from January 2012 to May 2014 in ten regions. The estimated averages, standard deviation and coefficient of variation for CBT, logCBT and sample age were 1,307,000 \pm 1.859 million (CFU / mL), 136.7\%; $5.89 \pm 1.93$ (log10UFCxmL-1), 29.5\% \pm 1.48 and 2.95 days, respectively. The effects included in the mathematical model influenced significantly $(p$ $<0.01)$ the variables studied. Lower values for logCBT occurred in late winter and spring (ranging from 5.36 and $5.47(\log 10 \mathrm{UFCxmL}-1)$ ). Over the years, there was a decrease in values (5.66 to 5.51 (log10UFCxmL-1)). The region significantly influenced the logCBT ( $p$ $<0.01$ ), recording the lowest average of 3.64 in Campo Mourao and the highest 6.44 $(\log 10 U F C x m L-1)$ in the Metropolitan of Curitiba, justified by different levels of technologies adopted in differents regions. The score of Somatic Cell Count (ECS) influenced significantly $(p<0.01)$ the CBT and the logCBT. When the age of the sample varied from zero to two days logCBT increased from 5.46 to 5.66 ( $x$ log10 CFU ml-1) and from three to seven days decreased from 5.66 to 5.57 ( $x \log 10$ CFU ml-1). Results show the need for producers, technicians and industry reassess their hygiene procedures of milking equipment, cooling, temperature and milk storage time, improving the microbiological quality of milk.

Key Words: age of the sample; month of analysis; region of analysis; somatic cell count; year of analysis 


\section{INTRODUÇÃO}

Segundo Mezzadri (2014), do Departamento de Economia Rural (DERAL) da Secretaria de Estado da Agricultura e Abastecimento (SEAB), o Estado do Paraná coloca-se como o $3^{\circ}$ maior produtor nacional de leite, com uma produção de 3,96 bilhões de litros, participando com $12 \%$ da produção brasileira, que em 2012, fechou na marca dos 32,3 bilhões de litros.

A caracterização socioeconômica da atividade leiteira do Paraná publicada pelo Instituto Paranaense de Desenvolvimento Econômico e Social (IPARDES) registrou a estimativa de 114.488 produtores de leite no Estado, sendo que $87 \%$, ou seja, 99.573 produtores comercializam a produção de leite e o restante, 14.915, apenas consomem o que produzem IPARDES (2009). Todavia, a caracterização racial do rebanho leiteiro paranaense apresenta: $28,4 \%$ de animais da raça Holandesa, 5,7\% Jersey, 17,7\% Girolanda, 8,0\% Pardo-Suíça e 40,2\% não possuem raça definida, segundo Koehler (2000).

A caracterização da indústria de processamento e transformação do leite no Paraná relata 353 unidades industriais processadoras e transformadoras de leite, localizadas em 180 municípios, sendo 101 unidades sob inspeção federal (SIF), 126 unidades sob inspeção estadual (SIP) e 126 unidades sob inspeção municipal (SIM) IPARDES (2010).

$\mathrm{Na}$ busca da produção de um leite com melhor qualidade foi implantado pelo Ministério da Agricultura, Pecuária e Abastecimento (MAPA) o Programa Nacional de Melhoria da Qualidade do Leite (PNMQL), por meio da Instrução Normativa $n^{\circ} .51$ Brasil (2002), visando adequar os produtos lácteos aos padrões internacionais, proteger 0 mercado interno da entrada de produtos de baixa qualidade, obter um produto competitivo no mercado internacional, assegurando o máximo de rendimento industrial e fornecer ao consumidor brasileiro um produto com maior valor nutritivo, maior durabilidade, mais seguro e de baixo custo.

Para o monitoramento mensal da qualidade do leite as indústrias de laticínios do Paraná em atendimento ao PNMQL do MAPA se utilizam dos serviços do Laboratório de Análise da Qualidade do Leite (LQL) do Programa de Análise de Rebanhos Leiteiros do Paraná (PARLPR) da Associação Paranaense de Criadores de Bovinos da Raça Holandesa (APCBRH), credenciado pelo MAPA e participante da Rede Brasileira da Qualidade do Leite (RBQL).

Em 2011 o MAPA alterou a IN 51 Brasil (2002), publicando em Diário Oficial da União de 30/12/2011 instrução normativa, IN 62 Brasil (2011), contendo normas de produção e qualidade do leite, começando a vigorar a partir de 01/01/2012 estabelecendo novos parâmetros para componentes do leite, contagem bacteriana total (CBT) e contagem de células somáticas (CCS).

Segundo Dürr et al. (2011), bases de dados do desempenho zootécnico de rebanhos são ferramentas essenciais para o manejo racional dos animais, para os programas de avaliação genética de gado leiteiro, programas de rastreabilidade de animais e produtos lácteos e para o planejamento estratégico da cadeia láctea.

A CBT do leite cru é um teste utilizado para avaliar a qualidade microbiológica do leite, indicando as condições de higiene na obtenção e no manuseio do leite nas propriedades. Altos valores indicam falhas na higiene dos equipamentos de ordenha, resfriamento, tempo e temperatura de armazenagem do leite, resultando em um produto com menor rendimento para queijo, diminuição do tempo de 
prateleira e falta de estabilidade dos produtos, prejudicando o processamento de derivados (Hill et al., 2011). Além disso, interfere na percepção de qualidade do leite e seus derivados pelo consumidor, de importância econômica para a cadeia agroindustrial (Santos e Fonseca, 2006). Assim, o objetivo desta pesquisa foi avaliar os efeitos de meio ambiente, caracterizados como mês, ano e região de análise, escore da contagem de células somáticas (ECS) e idade da amostra em dias, que estariam influenciando a CBT e logCBT de amostras de leite de tanque coletadas pelas indústrias de laticínios do Paraná.

\section{MATERIAL E MÉTODOS}

Para o estudo da CBT e logCBT, foram utilizadas 685.032 amostras refrigeradas de leite de tanques individuais, comunitários e latões coletadas pelas indústrias de laticínios em propriedades localizadas em 10 regiões no Estado do Paraná, analisadas no período de janeiro de 2012 a maio de 2014.

$\mathrm{Na}$ tabela 1, caracterizamos a localização das 10 regiões administrativas, seus municípios sede, classificação climática e temperatura média anual no Estado do Paraná, segundo IPARDES (2004).

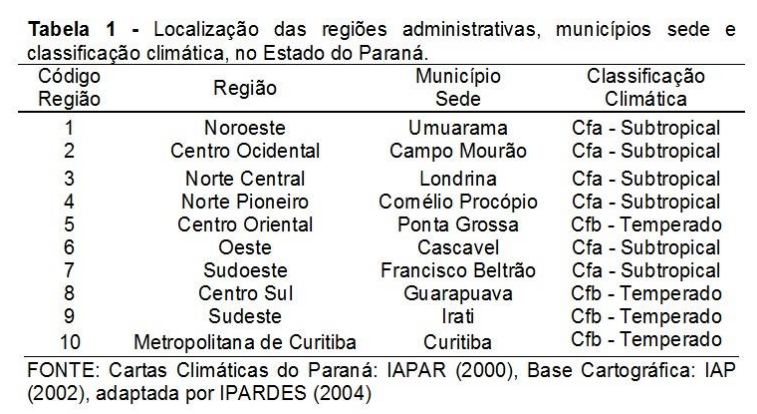

Segundo o IAPAR (2000), a classificação de Köppen identifica dois tipos climáticos no Estado do Paraná,
Cfa-subtropical e Cfb-temperado, descritos a seguir:

Cfa-Clima

subtropical;

temperatura média no mês mais frio inferior a $18^{\circ} \mathrm{C}$ (mesotérmico) e temperatura média no mês mais quente acima de $22^{\circ} \mathrm{C}$, com verões quentes, geadas pouco frequentes e tendência de concentração das chuvas nos meses de verão, contudo sem estação seca definida.

Cfb-Clima

temperado propriamente dito; temperatura média no mês mais frio abaixo de $18^{\circ} \mathrm{C}$ (mesotérmico), com verões frescos, temperatura média no mês mais quente abaixo de $22^{\circ} \mathrm{C}$ e sem estação seca definida.

As amostras de leite de tanques foram coletadas mensalmente nas propriedades por pessoal treinado pelas indústrias de laticínios, segundo os procedimentos recomendados pelos manuais de Operações de Campo (Horst, 2008) e de Coleta de Amostras (Horst, 2010) do LQL do PARLPR da APCBRH, Curitiba-PR. As amostras foram coletadas em frascos esterilizados $(70 \mathrm{~mL})$, utilizando-se 0 bacteriostático azidiol, para a CBT. Porém, para CCS as amostras foram coletadas em frascos, utilizando-se do conservante bronopol e enviadas ao LQL em caixa isotérmica com gelo para manter a temperatura abaixo de $7^{\circ} \mathrm{C}$. $\mathrm{O}$ número de dias decorridos entre a coleta de leite na fazenda e sua análise no LQL em Curitiba-PR, foi definido como sendo a idade da amostra.

Segundo Hartmann (1999), Ostrensky (1999) e Paula et al. (2004), visando melhor acurácia das análises para amostras de leite de bovinos, as seguintes restrições foram impostas ao banco de dados: CCS menor ou igual a zero e maior que 4.525 .000 células $/ \mathrm{mL}$; $\%$ de gordura menor que $1,5 \%$ e maior que $6,5 \%$; \% de proteína menor que $1,5 \%$ e maior que $6,5 \%$ e idade de amostra menor que um e maior que sete 
dias e para CBT menor ou igual a zero e maior que 9 milhões UFC/ mL.

A análise da característica estudada foi realizada utilizando-se do seguinte modelo estatístico:

eijklm

$Y i j k I m=\mu+M i+A j+R k+E C S I+I m+$

Em que:

Yijklm= observação referente à CBT e ao logCBT de amostras de leite de tanques, coletadas no mês i, no ano j, na região $\mathrm{k}, \mathrm{ECSm}$, com idade da amostra I e erro aleatório associado a cada observação eijklm, onde:

$$
\begin{aligned}
& \mu \quad=\text { média geral; } \\
& \text { Mi = efeito do mês de análise i, } \\
& \text { sendo } \mathrm{i}=1 \text { (jan), } 2 \text { (fev), ..., } 12 \\
& \text { (dez); } \\
& \mathrm{Aj} \quad=\text { efeito do ano de análise } \mathrm{j} \text {, } \\
& \text { sendo j = 2012, } 2013 \text { e 2014*; } \\
& \mathrm{Rk} \quad=\text { efeito da região de análise } \\
& \mathrm{k} \text {, sendo } \mathrm{k}=1,2, \ldots, 10 \text {; } \\
& \mathrm{ECSI}=\text { escore da contagem de }
\end{aligned}
$$

*o ano de 2014 está representado apenas por amostras de leite coletadas nos cinco primeiros meses do ano.

A CBT é expressa em unidades formadoras de colônia por mililitros de leite (UFC/mL), realizada por citometria de fluxo no equipamento Bactocount IBC®, cuja capacidade é de até 150 amostras/hora Bentley Instruments (2002). Todavia a variável CCS é o resultado da leitura do equipamento por citometria de fluxo, Somacount $300 \AA$ Bentley Instruments (1995), em mil células/ $\mathrm{mL}$. O escore da contagem de células somáticas (ECS) é o resultado da transformação logarítmica da CCS, segundo Ali \& Shook, (1980), Shook
(1982), obtida pela equação ECS = $\log 2(\mathrm{CCS} / 100)+3$.

Os valores de ECS correspondentes ao intervalo de CCS de zero a 12.000 células $/ \mathrm{mL}$ foram forçados a serem iguais a zero, para se evitarem números negativos. A CBT foi transformada em logarítmico (log10 UFC $\times \mathrm{mL}-1$ ).

A transformação logarítmica da CBT (x1.000 UFC/mL) para logCBT ( $\log 10$ UFC x mL-1), segundo Lopes Júnior et al. (2012); Alberton et al., (2012) e Takahashi, (2012), mostra maior precisão nas análises estatísticas, maior coeficiente de determinação, menor coeficiente de variação e menores erros-padrão.

A análise dos dados foi realizada adotando-se o programa computacional SAS® versão 9.3 (2011) pelo modelo estatístico tipo III, utilizando-se dos seguintes procedimentos Proc Means, Proc Freq, Proc GLM e Proc Corr. A

\begin{tabular}{|c|c|c|c|c|c|}
\hline Características & N & Média & \pm & DP & CV (\%) \\
\hline $\mathrm{CBT}^{1}$ & 680102 & 1.307 & \pm & 1.859 & 136,7 \\
\hline $\log C B T$ & 680102 & 5,89 & \pm & 1,93 & 29,5 \\
\hline Idade da amostra (dias) & 680102 & 2,95 & \pm & 1,48 & - \\
\hline
\end{tabular}
comparação entre médias foi realizada por meio do Teste de Tukey a $1 \%$ de probabilidade.

\section{RESULTADOS E DISCUSSÃO}

As médias observadas, os respectivos desvios padrão e os coeficientes de variação da CBT e logCBT e idade da amostra foram: 1.307 \pm 1.859 (x1.000 UFC/mL), 136,7\%; 5,89 $\pm 1,93,29,5 \% ; 2,95 \pm 1,48$ dias em amostras de leite de tanques individuais, comunitários ou de latões analisados no período de 2012 a 2014, que encontram-se na tabela 2.

${ }^{1}(\mathrm{x} 1.000$ UFC $/ \mathrm{mL})$ 
As médias encontradas nesta pesquisa superam os valores exigidos pela IN 62 do MAPA (Brasil, 2011), que estabeleceu novos limites para a CBT (média geométrica dos resultados de três meses em UFC/mL) para amostras de tanque de acordo com as regiões do Brasil e datas de vigor. Assim, para as regiões Sul, Sudeste e Centro-Oeste do Brasil o limite estabelecido foi de 300.000 UFC/mL a partir de julho de 2014.

O estudo de frequências das amostras da CBT (x1.000 UFC/mL) segundo as classes estabelecidas se encontra na tabela 3. Nesta, observa-se que $64,55 \%$ das amostras se enquadram na classe seis (501 a 1.000 $\mathrm{x} 1.000 \mathrm{UFC} / \mathrm{mL}$ ). Estes, estão muito a quem daqueles estabelecidos pelos serviços de controle de rebanhos leiteiros dos Estados Unidos e Canadá, que tem como meta atingir no máximo classe dois (26 a $50 \times 1.000 \mathrm{UFC} / \mathrm{mL}$ ), ou seja, que os rebanhos apresentem até 50 mil UFC/mL no leite, pois, segundo Silva (2014), estes valores já são considerados elevados, merecendo atenção dos produtores.

Em países que estabeleceram programas de melhoria da qualidade do leite como o Canadá, EUA e da União Europeia, as unidades formadoras de colônias são muito inferiores (28.000 a $37.753 \mathrm{UFC} / \mathrm{mL}$ ), àquelas publicadas por autores brasileiros (138.038 a 2.690.000 UFC/mL) que se encontram na tabela 4.

Segundo Hillerton e Berry (2004), os EUA e a União Europeia adotaram o limite legal de 100.000 UFC/ml. No Reino Unido em 2003 as médias mensais no verão foram de 28.000 a 35.000 UFC/mL.

Os resultados encontrados neste trabalho quando comparado com países de pecuária leiteira desenvolvida são muito altos, refletindo pouco cuidado dos produtores técnicos e das indústrias brasileiras com relação à avaliação da qualidade microbiológica do leite, dificultando a industrialização, resultando em um produto com menor qualidade e rendimento para o queijo, diminuição do tempo de prateleira e falta de estabilidade dos produtos, prejudicando 0 processamento de derivados (Hill et al., 2011).

\begin{tabular}{|c|c|c|c|c|}
\hline $\begin{array}{l}\text { Classes } \\
\text { CBT }\end{array}$ & $\begin{array}{c}\text { Variação da } \\
\text { CBT }^{1}\end{array}$ & $\mathrm{~N}$ & $\begin{array}{c}\% \% \\
\text { classe }\end{array}$ & $\begin{array}{c}\% \% \\
\text { acumulada }\end{array}$ \\
\hline 1 & 0 a 25 & 74393 & 10,94 & 10,94 \\
\hline 2 & 26 a 50 & 45246 & 6,65 & 17,59 \\
\hline 3 & 51 a 100 & 56430 & 8,30 & 25,89 \\
\hline 4 & 101 a 250 & 90923 & 13,37 & 39,26 \\
\hline 5 & 251 a 500 & 81799 & 12,03 & 51,29 \\
\hline 6 & 501 a 1.000 & 90196 & 13,26 & 64,55 \\
\hline 7 & 1.001 a 2.500 & 116357 & 17,11 & 81,66 \\
\hline 8 & 2.501 a 5.000 & 79207 & 11,65 & 93,30 \\
\hline 9 & 5.001 a 9.000 & 45551 & 6,70 & 100,00 \\
\hline TOTAL & & 680102 & & \\
\hline
\end{tabular}
Tabela 4 - Valores médios de Contagem Bacteriana Total (CBT) obtidos por

\begin{tabular}{lccc}
\hline \multicolumn{1}{c}{ Autor (Ano) } & Pais & $\begin{array}{c}\mathrm{N}^{\circ} \text { de } \\
\text { Observações }\end{array}$ & $\begin{array}{c}\text { CBT } \\
\text { (UFC/mL) }\end{array}$ \\
\hline Bueno et al. (2008) & Brasil & 16.491 & 2.690 .000 \\
Córdova et al. (2007) & Brasil & 133.104 & 2.676 .000 \\
Hill et al. (2011) & Brasil & 87.575 & 2.378 .000 \\
Borges et al. (2009) & Brasil & 143 & 1.070 .000 \\
Beloti et al. (2012) & Brasil & - & 708.630 \\
Fonseca et al. (2006) & Brasil & 320.000 & 646.000 \\
Borges et al. (2013) & Brasil & 67 & 676.000 \\
Alberton et al. (2012) & Brasil & 18.366 & 660.693 \\
Hoogerheide et al.(2012) & Brasil & 27.978 & 512.000 \\
Martins et al. (2008) & Brasil & 14 & 453.000 \\
Luz et al. (2011) & Brasil & 10 & 345.200 \\
Agüero et al. (1989) & Chile & 25 & 287.956 \\
Revelli et al. (2004) & Argentina & 6.998 & 120.000 \\
Revelli et al. (2011) & Argentina & 9.899 & 96.000 \\
FPLQ (2012) & Canadá & 1.589 .344 & 38.727 \\
FPLQ (2011) & Canadá & 1.620 .080 & 37.753 \\
Hillerton e Berry (2004) & Reino Unido & - & 28.000 \\
\hline
\end{tabular}

O resumo de análise de variância para as duas características estudadas encontra-se na tabela 5 . Todos os efeitos incluídos no modelo estatístico foram significativos $(P<0,001)$. Nesta, observamos maior $\mathrm{R}^{2}$, menores $\mathrm{CV} \% \mathrm{e}$ erros-padrão pela adoção da transformação logarítmica da CBT.

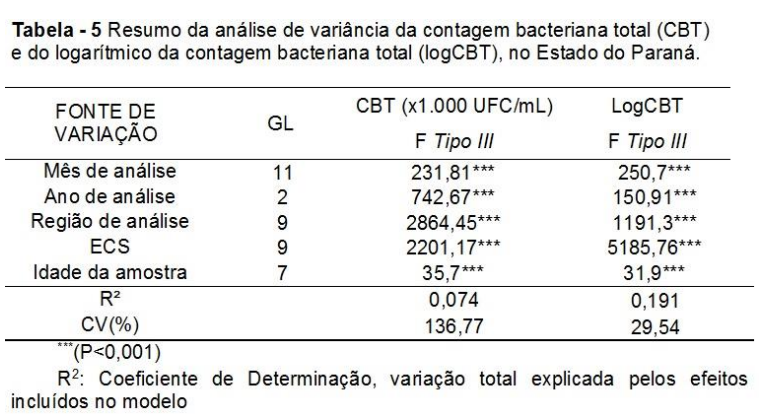


No resumo da análise de variância (tabela 5 ), observamos que o efeito do mês de análise influenciou significativamente as variáveis CBT e $\log C B T(P<0,001)$. Na tabela 6 observase que as maiores estimativas de médias ajustadas para na CBT (1.559 x $1.000 \mathrm{UFC} / \mathrm{mL})$ e $\log C B T(5,86 \log 10$ UFC $\times$ mL-1) ocorreram nos meses de Janeiro, Fevereiro e Março (verão). Todavia, as menores estimativas na CBT (1.268 x $1.000 \mathrm{UFC} / \mathrm{mL})$ e logCBT $(5,36 \log 10$ UFC $\times \quad \mathrm{mL}-1)$ foram encontradas nos meses de Agosto, Setembro e Outubro (final de inverno e início da primavera). Estes resultados foram semelhantes àqueles relatados anteriormente por Córdova et al., (2007), Bueno et al., (2008), Guimarães (2008), Borges et al., (2009), Hill et al., (2011) e Alberton et al., (2012).

De acordo com os autores o período das chuvas (maior umidade ambiental e precipitação pluviométrica), favorece o aumento da contaminação ambiental, o acúmulo de lama nas instalações e maior ocorrência de tetos sujos no momento da ordenha. Bem como, o resfriamento inadequado, a qualidade da água para limpeza e desinfecção dos equipamentos, a não utilização de detergentes e desinfetantes adequados na antissepsia dos tetos e o estado de conservação dos insufladores, favorecendo a multiplicação bacteriana, justificando maiores CBT no verão. Todavia, Andrade et.al., (2014), avaliando as estações do ano, não encontrou diferenças significativas na contagem bacteriana total do leite cru de tanques de expansão no agreste do estado do Rio Grande do Norte, justificando pela higiene do recinto e manejo de ordenha que favoreceram a ausência de diferença nos níveis de CBT.
Tabela 6 - Número de observações (N), número de observações acumuladas (\%), estimativas das médias ajustadas e erros-padrão (EP) pelo método dos quadrados mínimos da contagem bacteriana total (CBT) e logarítmico da contagem bacteriana total (logCBT), segundo o mês de análise.

\begin{tabular}{|c|c|c|c|c|c|c|c|c|}
\hline \multirow{2}{*}{$\begin{array}{l}\text { Mês de } \\
\text { Análise }\end{array}$} & \multirow{2}{*}{$\mathrm{N}$} & \multirow{2}{*}{$\%$} & \multicolumn{3}{|c|}{ CBT (x1.000 UFC/mL) } & \multicolumn{3}{|c|}{$\log \mathrm{CBT}$} \\
\hline & & & Média $^{1}$ & \pm & EP & Média ${ }^{1}$ & \pm & $E P$ \\
\hline Janeiro & 60387 & 8,88 & $1.559^{a}$ & \pm & 12.67 & $5,86^{a}$ & \pm & 0,01 \\
\hline Fevereiro & 56090 & 17,13 & $1.397^{b}$ & \pm & 12,74 & $5,67^{b}$ & \pm & 0,01 \\
\hline Março & 58658 & 25,75 & $1.419^{b c}$ & \pm & 12,73 & $5,67^{b}$ & \pm & 0,01 \\
\hline Abril & 57438 & 34,20 & $1.365^{b c}$ & \pm & 12,79 & $5,53^{c}$ & \pm & 0,01 \\
\hline Maio & 58978 & 42,87 & $1.446^{\mathrm{bcd}}$ & \pm & 12,69 & $5,61^{d}$ & \pm & 0,01 \\
\hline Junho & 51269 & 50,41 & $1.467^{\mathrm{de}}$ & \pm & 12,94 & 5,67 be & \pm & 0,01 \\
\hline Julho & 56275 & 58,68 & $1.342^{c f}$ & \pm & 12,92 & $5,49^{f}$ & \pm & 0,01 \\
\hline Agosto & 54945 & 66,76 & $1.268^{g}$ & \pm & 12,88 & $5,36^{9}$ & \pm & 0,01 \\
\hline Setembro & 56015 & 75,00 & $1.315^{\text {fh }}$ & \pm & 12,70 & $5,53 \mathrm{ch}$ & \pm & 0,01 \\
\hline Outubro & 57512 & 83,45 & $1.265^{\mathrm{gi}}$ & \pm & 12,67 & $5,55^{\text {ci }}$ & \pm & 0,01 \\
\hline Novembro & 58203 & 92,01 & $1.111^{\mathrm{j}}$ & \pm & 12,63 & $5,47^{\mathrm{djj}}$ & \pm & 0,01 \\
\hline Dezembro & 54332 & 100,00 & $1.156^{k}$ & \pm & 12,84 & $5,59 \mathrm{ek}$ & \pm & 0,01 \\
\hline Total & 680102 & & & & & & & \\
\hline
\end{tabular}

O efeito de ano de análise influenciou significativamente as variáveis CBT e logCBT $(P<0,001)$, como pode-se observar no resumo de análise de variância (tabela 5).

$\mathrm{Na}$ tabela 7, encontram-se as médias ajustadas e nesta, observamos uma tendência de menores valores com o passar dos anos de 2012 a 2014 $(1.511 \times 1.000$ UFC/mL e 5,66 log10 UFC $\times \mathrm{mL}-1)$ para $(1.161 \times 1.000$ UFC/mL e 5,51 log10 UFC $x \quad \mathrm{~mL}-1$ ) respectivamente. Resultados semelhantes foram relatados por Revelli et al., (2004), Revelli et al., (2011), Alberton et al., (2012) e FPLQ (2012), que justificaram a diminuição da CBT com a aquisição de unidades de refrigeração, programas de pagamento por qualidade, implantação de programas de capacitação melhorando correções nos aspectos higiênicos da coleta, armazenagem e resfriamento do leite, permitindo o cumprimento dos limites estabelecidos pela IN 62 BRASIL (2011).

Em 2012, segundo a Fédération des Producteurs de Lait du Québec FPLQ (2012), o percentual de leite em conformidade com a norma de contagem bacteriana total (CBT) situouse em 97,50\%, em comparação com $97,39 \%$ de 2011. A média ponderada anual da CBT no leite foi de 38.727 UFC/mL, em comparação com 37.753 UFC/mL em 2011. 


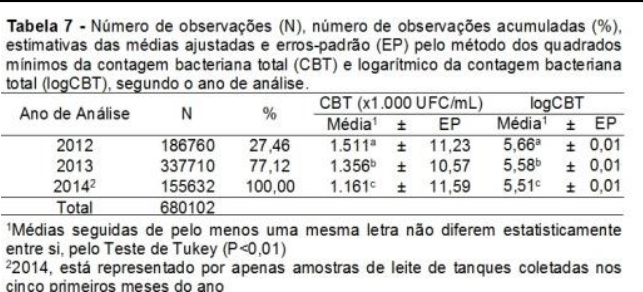

entre si, pelo Teste de Tukey $(P<0$
22014 , está representado por ape
cinco primeiros meses do ano

Também o efeito de região de análise, influenciou significativamente as variáveis estudadas $(P<0,001)$, como se observa no resumo de análise de variância (tabela 5).

As médias ajustadas e os respectivos erros-padrão para as dez regiões estudas estão descritas na tabela 8. Nesta, observamos que as menores estimativas foram de 557 $(x 1.000$ UFC/mL) e 3,64 $(\log 10$ UFC x $\mathrm{mL}-1)$ para a região Centro Ocidental Campo Mourão e as maiores de 1.971 $(x 1.000$ UFC/mL) e 6,44 $(\log 10$ UFC x $\mathrm{mL}-1)$ para Metropolitana de Curitiba, respectivamente.

Diferenças significativas entre regiões, também foram relatadas anteriormente por Córdova et al., (2007), Hartmann, (2009), Vallin et al., (2009), Hill et al., (2011), Alberton et al., (2012), Beloti et al., (2012), Hoogerheide e Mattioda (2012) e justificadas por diferentes tipos de clima entre as regiões, instalações e níveis de tecnologias adotadas pelos produtores. Os resultados evidenciam a necessidade por parte dos produtores, técnicos e indústrias da adoção dos programas de boas práticas de higiene, rastreando os principais pontos de contaminação microbiológica do leite, reavaliando seus procedimentos de higiene dos equipamentos de ordenha, resfriamento, temperatura e tempo de armazenagem do leite, visando 0 cumprimento do limite da CBT estabelecido pela IN 62/MAPA de $300.000 U F C / m L$ para o período de julho/2014 a junho/2016 (BRASIL, 2011).

Bem como, caberia também à indústria recompensar financeiramente os produtores por um produto que the traz maior rendimento, diminuição de problemas tecnológicos e maior lucratividade pela adoção de programas de pagamento por qualidade focando a CBT.

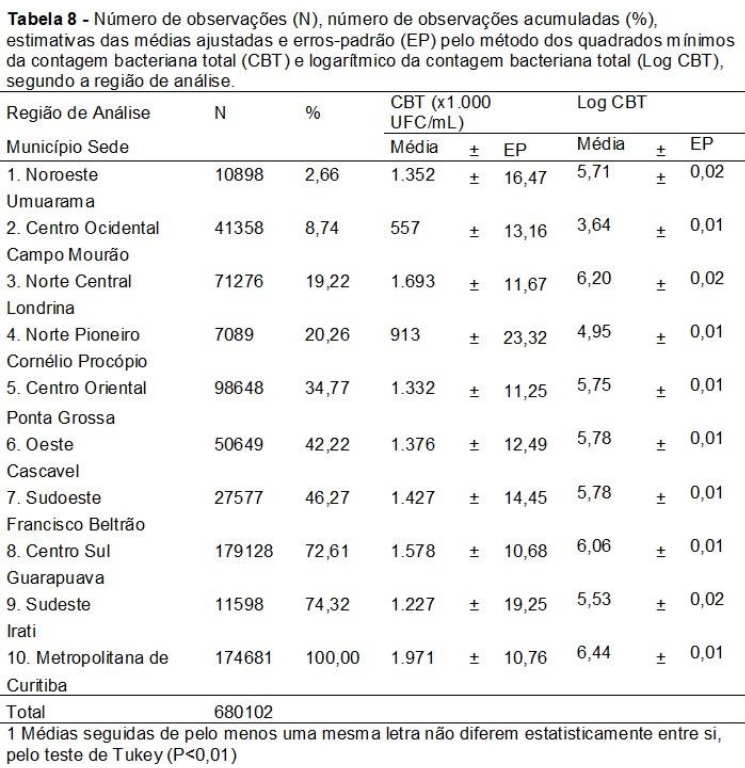

$O$ efeito de ECS influenciou significativamente $(P<0,001)$ as duas variáveis estudadas como podemos observar no resumo de análise de variância (tabela 5). Na tabela 9, apresentamos as relações entre o ECS variando de 0 a 9 com suas respectivas médias ajustadas para CBT e logCBT. Nesta, observamos que quando o ECS variou de zero para nove (de zero para acima 4.525.000 células $/ \mathrm{mL}$ ) a CBT aumentou de 461 para 3.451(x1.000UFC/mL) e o logCBT de 4,05 para $7,46(\log 10$ UFC $\times \mathrm{mL}-1)$. Ficando evidente, uma associação linear entre as duas variáveis, ou seja, conforme aumenta a quantidade de CCS no leite, aumentaram os valores da CBT e do logCBT.

Diferenças significativas entre a CBT, logCBT e o ECS, também foram relatadas anteriormente por diversos 
autores, entre eles Suhren \& Walte (2000), Schaik et al., (2005), Colla (2009), Alberton et al., (2012) e Bozo et al., (2013), que justificaram as diferenças pela associação linear entre as duas variáveis. Pois, CCS maiores que um milhão de células/ml estão correlacionadas positivamente com 0 aumento da CBT do leite, refletindo deficiências nas boas práticas de ordenha e na higiene dos equipamentos de ordenha.

Todavia, conflitando com tais resultados, Lima et al., (2006), não encontraram variação bacteriana significativa em diferentes intervalos de CCS e destacaram não haver necessariamente relação entre CCS e CBT no leite. Os mesmos autores ainda citam que, a alta CBT observada, mesmo com CCS abaixo de $400.000 / \mathrm{mL}$.

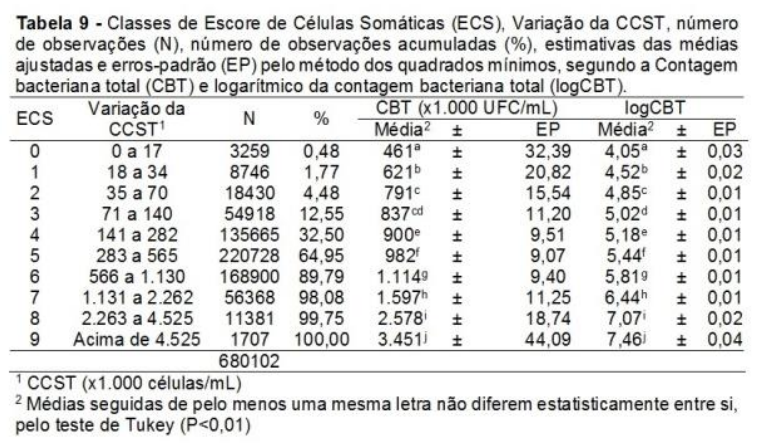

$\mathrm{Na}$ tabela 10, apresentamos os coeficientes de correlação de Pearson obtidos entre a CBT, logCBT e o ECS, que foram médios e positivos de 0,155 $(\mathrm{P}<0,001) \quad$ e $\quad 0,267 \quad(\mathrm{P}<0,001)$, respectivamente. Colla (2009) e Alberton et al., (2012), também encontraram correlações positivas entre CCS e CBT de 0,852 e 0,129 ( $P<0,01)$, respectivamente. Sugerindo associação linear entre as duas variáveis.
Tabela 10 - Coeficientes de Correlação de Pearson entre a Contagem Bacteriana Total (CBT), Logarítmico da Contagem Bacteriana Total (logCBT) e o Escore da Contagem de Células Somáticas (ECS).

\begin{tabular}{cc} 
Contagem de Células Somáticas (ECS). & ECS \\
\cline { 2 - 2 } Características & Correlação $(r)$ \\
\hline CBT $(x 1.000$ UFC $/ \mathrm{mL})$ & $0,155^{\star \star \star}$ \\
$\log \mathrm{CBT}$ & $0,267^{\star \star \star}$ \\
\hline${ }^{\star \star *}(\mathrm{P}<0,001)$ &
\end{tabular}

Também o efeito de idade da amostra em dias, influenciou significativamente as variáveis estudadas $(P<0,001)$, como podemos observar no resumo de análise de variância (tabela 5). $\mathrm{Na}$ Tabela 11, as médias de idade da amostra, evidenciam que quando esta variou de zero a dois dias as médias da CBT e logCBT aumentaram de 1.355(x1.000 UFC/mL), 5,46 para 1.411(x1.000 UFC/mL), 5,66 $(\log 10$ UFC $x \mathrm{~mL}-1)$ e de três para sete dias, diminuíram de 1.367(x1.000 UFC/mL), 5,66 para $1.266(x 1.000 \mathrm{UFC} / \mathrm{mL}), \quad 5,57$ $(\log 10$ UFC $x \mathrm{~mL}-1)$. Ficando evidente a necessidade de maior controle da temperatura de refrigeração (ideal entre $1^{\circ} \mathrm{C}$ e $7^{\circ} \mathrm{C}$.) das amostras, evitando $\mathrm{o}$ aquecimento ou congelamento por ocasião do transporte e estocagem.

\begin{tabular}{|c|c|c|c|c|c|c|c|c|}
\hline \multirow{2}{*}{$\begin{array}{l}\text { Idade Amostra } \\
\text { (em dias) }\end{array}$} & \multirow[t]{2}{*}{$\mathrm{N}$} & \multirow[t]{2}{*}{$\%$} & \multicolumn{3}{|c|}{$\begin{array}{l}\text { CBT }(x 1.000 \\
\text { UFC } / \mathrm{mL})\end{array}$} & \multicolumn{3}{|c|}{$\log \mathrm{CBT}$} \\
\hline & & & Média & \pm & EP & Média & \pm & EP \\
\hline 0 & 889 & 0,13 & $1.355^{\text {a }}$ & \pm & 60,36 & $5,46^{a}$ & \pm & 0,06 \\
\hline 1 & 97648 & 14,49 & $1.367 \mathrm{ab}$ & \pm & 8,88 & $5,60^{\mathrm{a}}$ & \pm & 0,01 \\
\hline 2 & 224851 & 47,55 & $1.411^{\mathrm{ab}}$ & \pm & 7,59 & $5,66^{b}$ & \pm & 0,01 \\
\hline 3 & 147340 & 69,21 & $1.367^{a b}$ & \pm & 7,98 & $5,60^{b c}$ & \pm & 0,01 \\
\hline 4 & 85688 & 81,81 & $1.326^{a c}$ & \pm & 8,94 & $5,58^{\mathrm{bcd}}$ & \pm & 0,01 \\
\hline 5 & 78175 & 93,31 & 1.337 ac & \pm & 9,21 & $5,61^{\text {bod }}$ & \pm & 0,01 \\
\hline 6 & 35199 & 98,48 & $1.310^{a c}$ & \pm & 11,72 & $5,56^{\text {bcde }}$ & \pm & 0,01 \\
\hline 7 & 10312 & 100,00 & $1.266^{a c}$ & \pm & 18,92 & $5,57^{\text {bcde }}$ & \pm & 0,02 \\
\hline TOTAL & 680102 & & & & & & & \\
\hline
\end{tabular}

Resultados semelhantes, foram relatados por Cassoli et al., (2004) e Martins et al., (2009), registrando que no nível de contaminação <105 UFC/mL, as amostras conservadas com azidiol mostraram-se viáveis para análise até o sexto dia de armazenagem, sem comprometimento ou alteração significativa na qualidade da amostra por efeito de estocagem, quando submetidas à temperatura entre $1,8^{\circ} \mathrm{C} \mathrm{e}$ $4,2^{\circ} \mathrm{C}$, demonstrando que o conservante azidiol, possui estabilidade de ação para essa variável. Bem como, Cassoli 
(2005), considera que a amostra para determinação de CBT pode ser analisada em até sete dias após a coleta, desde que conservadas com azidiol, mantidas sob refrigeração até $7^{\circ} \mathrm{C}$, evitando-se $\mathrm{o}$ aquecimento ou congelamento da amostra.

\section{CONCLUSÃO}

Os resultados evidenciam a necessidade por parte dos produtores, técnicos e indústrias de reavaliarem seus procedimentos focando a qualidade microbiológica do leite como a higiene dos equipamentos de ordenha, resfriamento, temperatura, tempo de armazenagem e coleta do leite.

A maioria das amostras de leite analisada apresenta-se fora dos padrões exigidos pela IN 62 do MAPA no que se refere à CBT. Dessa forma, para mudar esta realidade, faz-se necessária a adoção de programas de educação continuada focando boas práticas de higiene, saúde da glândula mamária e a qualidade microbiológica do leite para produtores das regiões estudadas.

\section{NOTAS INFORMATIVAS}

A Comissão de Ética no Uso de Animais (CEUA) do Setor de Ciências Agrárias (SCA) da Universidade Federal do Paraná (UFPR) aprovou o projeto através do protocolo 024/2011.

\section{AGRADECIMENTOS}

Ao Laboratório de Análise da Qualidade do Leite do Programa de Análise de Rebanhos Leiteiros do Paraná - PARLPR da Associação Paranaense de Criadores de Bovinos da Raça Holandesa - APCBRH, fruto da cooperação técnica e científica com a
Universidade Federal do Paraná UFPR, pela cessão do banco de dados e pela valiosa colaboração.

Ao FUNDO PARANÁ da Secretaria da Ciência, Tecnologia e Ensino Superior, Curitiba-PR, pelo apoio financeiro através dos convênios números 01/07 e 19/07, com a Fundação da Universidade Federal do Paraná para o Desenvolvimento da Ciência, da Tecnologia e da Cultura, que possibilitaram a realização deste projeto de pesquisa.

\section{REFERÊNCIAS}

AGÜERO, E.H.; PEDRAZA, G.C.; SUAZO, D.X. Evaluación bacteriológica de leche almacenada en estanques prediales. Agricultura Técnica. Chile, v.49, n.4, p.291-297, 1989.

ALBERTON, J.; ALBERTON, L.R.; PACHALY, J.R.; OTUTUMI, L.K.; ZAMPIERI, T.M.; AGOSTINIS, R.O. Estudo da qualidade do leite de amostras obtidas de tanques de resfriamento em três regiões do estado do Paraná. Arquivos de Ciências Veterinárias e Zoologia da UNIPAR. Umuarama, v.15, n.1, p.5-12, 2012.

ALI, A.K.A.; SHOOK, G.E. $\mathrm{Na}$ optimum transformation for somatic cell concentration in milk. Journal of Dairy Science, v.63, p.487-490, 1980.

ANDRADE, K.D.; RANGEL, A.H.N.; ARAÚJO, V.M.; et al.; Qualidade do leite bovino nas diferentes estações do ano no estado do Rio Grande do Norte. Revista Brasileira de Ciência Veterinária, v.21, n.3, p.213-216, 2014.

ANDRADE, U.V.C.; HARTMANN, W.; MASSON, M.L. Isolamento microbiológico, contagem de células somáticas e contagem bacteriana total em amostras de leite. ARS Veterinaria, Jaboticabal - São Paulo, v.25, n.3, p.129-135, 2009.

BELOTI, V.; JÚNIOR, R.C.J.; TAMANINI, R.; et al.; Impacto da implantação de boas práticas de higiene na ordenha sobre a qualidade microbiológica e físico-química do leite cru refrigerado. Revista do Instituto de Laticínios Cândido Tostes, Juiz de Fora, v.67, n.388, p.0510, 2012.

BENTLEY INSTRUMENTS. Somacount 300 operator's manual. Chaska - EUA, Bentley Instruments INC, p12, 1995b. 
BENTLEY INSTRUMENTS INC. BactoCount 150 operator's manual. Chaska -EUA, Bentley Instruments INC., p.49, 2002.

BORGES, L.R.; FONSECA, L.M.; MARTINS, R.T.; et al. Milk quality according to the daily range in farm production in the Mesoregion Central Mineira and Oeste of Minas Gerais regions, Brazil. Arquivo Brasileiro de Medicina Veterinária e Zootecnia, Belo Horizonte, v.65, n.4, p.1239-1246, 2013.

BORGES, K.A.; REICHERT, S.; ZANELA, M.B.; et al:; Avaliação da qualidade do leite de propriedades da região do Vale do Taquari no estado do Rio Grande do Sul. Acta Scientiae Veterinariae. v.37, n.1, p.39-44, 2009.

BOZO, G.A.; ALEGRO, L.C.A.; SILVA, L.C.; et al.; Adequação da contagem de células somáticas e da contagem bacteriana total em leite cru refrigerado aos parâmetros da legislação. Arquivo Brasileiro de Medicina Veterinária e Zootecnia, Belo Horizonte, v.65, n.2, p.589-594, 2013.

BRASIL. Ministério da Agricultura, Pecuária e do Abastecimento. Altera a Instrução Normativa $\mathrm{n}=51 / 2002$. Estabelece novos prazos e limites para a redução de CBT e CCS até o ano de 2016, chegando aos valores de $100 \mathrm{mil} / \mathrm{ml}$ e 400 $\mathrm{mil} / \mathrm{ml}$, respectivamente. Suprime os Regulamentos Técnicos de Identidade e Qualidade dos leites tipos "B" e "C". Portaria $\mathrm{n}^{\circ}$ 62, de 30 de dezembro de 2011. Diário Oficial da República Federativa do Brasil, Brasília, DF, no. 251, 30 dez. 2011.

BRASIL. Portaria $\mathrm{n} \div 51$, do Ministério da Agricultura e do Abastecimento, de 18 de setembro de 2002. Aprova os regulamentos técnicos de produção, identidade e quantidade do leite tipo $A$, do leite tipo $B$, do leite tipo $C$, do leite pasteurizado e do leite cru refrigerado e o regulamento técnico da coleta de leite cru refrigerado e seu transporte a granel, em conformidade com os anexos a esta Instrução Normativa. Diário Oficial da Republica do Brasil, Brasília, n.321, 20 set., 2002.

BUENO, V.F.F.; MESQUITA, A.J.; OLIVEIRA, A.N.; et al.; Contagem bacteriana total do leite: relação com a composição centesimal e período do ano no Estado de Goiás. Revista Brasileira de Ciências Veterinárias, v.15, n.1, p.40-44, 2008.

CASSOLI, L. D.; MACHADO, P. F.; COLDEBELLA, A. Efeito da temperatura e do tempo de armazenamento sobre a contagem individual de bactérias em amostras de leite conservadas com azidiol. In: CONGRESSO BRASILEIRO DE QUALIDADE DO LEITE, 1,
2004, Passo Fundo. Anais eletrônicos...[CDROM], Passo Fundo: UPF, 2004.

CASSOLI, L.D. Validação da metodologia de citometria de fluxo para avaliação da contagem bacteriana do leite cru. 2005, São Paulo, $46 f$. Dissertação (Mestrado em Agronomia) - Escola Superior de Agricultura Luiz de Queiroz, Universidade de São Paulo.

COLLA, M.F. Valor da haptoglobina no plasma comparado com a contagem de células somáticas do leite no diagnóstico da mastite subclínica em vacas leiteiras. 2009, Rio Grande do Sul, 67f. Dissertação (Mestrado em Ciências Veterinárias) - Universidade Federal do Rio Grande do Sul.

CÓRDOVA, H.A.; COSTA FILHO, O.; HILGEMBERG, E.M. Qualidade do leite no Estado do Paraná. 2007. Disponível em: < http://www.escoladegoverno.pr.gov.br/arquivos/ File/anais/painel_agricultura/programa_de_melh oria_da_qualidade.pdf $>$. Acesso em: 20/01/2015.

DÜRR, J.W.; RIBAS, N.P.; COSTA, C.N.; et al.; Milk recording as an indispensable procedure to assure Milk quality. Revista Brasileira de Zootecnia, Viçosa, v. 40, p. 76-81, 2011.

FAGNANI, R.; BATTAGLINI, P.P.A.; BELOTI, V.; et al.; Parâmetros físico-químicos e microbiológicos do leite em função da sazonalidade. Revista do Instituto de Laticínios Cândido Tostes, Juiz de Fora, v. 69, n.3, p.173180, 2014.

FONSECA, L.M.; RODRIGUES, R.; CERQUEIRA, M.M.O.P.; et al.; Situação da qualidade do leite cru em Minas Gerais. In: MESQUITA, A.J., DURR, J.W., COELHO, K.O. Perspectivas e avanços da qualidade do leite no Brasil. Goiânia: Talento, v.1, p.23-37, 2006.

FPLQ. Le Cycle De Vie Du Lait. Fédération des Producteurs de Lait du Québec, Rapport annuel 2012, p. 23, 2012. Disponível em: <http://www.lait.org/fichiers/RapportAnnuel/FPL Q-2012/RapportAnnuel2012.pdf>.

Acesso em: 14/05/2015.

FPLQ. Le lait, source durable de développement. Fédération des Producteurs de Lait du Québec, Rapport annuel 2011, p. 26, $2011 . \quad$ Disponível em: <http://www.lait.org/fichiers/RapportAnnuel/FPL Q-2011/RapportAnnuel2011.pdf>.

Acesso em: 07/03/2015.

GUIMARÃES, C.P.A. Impacto da assistência técnica sobre a qualidade do leite. 2008. Goiânia, 82f. Dissertação (Mestrado em 
Medicina Veterinária) - Universidade Federal de Goiás.

HARTMANN, W. Sólidos totais em amostras de leite de tanques. 1999. Curitiba, 56f. Dissertação (Mestrado em Ciências Veterinárias) - Curso de Pós-Graduação em Ciências Veterinárias, Universidade Federal do Paraná.

HARTMANN, W. Características físico-químicas, microbiológicas, de manejo e higiene na produção de leite bovino na região oeste do Paraná: ocorrência de Listeria monocytogenes. 2009. Curitiba, 76f. Tese (doutorado) Programa de Pós-Graduação em Tecnologia de Alimentos, Universidade Federal do Paraná.

HILL, J. A. G.; SILVEIRA, A. L. F. da; MIGLIORINI, F.; et al.; Qualidade do leite na região sudoeste do Paraná. Londrina: IAPAR, 2011. 56 p. (IAPAR, Boletim técnico, 76).

HILLERTON, J.E. E BERRY, E.A. Quality of the milk supply: european regulations versus practice. NMC Annual Meeting Proceedings, 2004, p.207-214,

HOOGERHEIDE, L.S.; MATTIODA, F. Qualidade bacteriológica do leite cru refrigerado em propriedades rurais do estado do Paraná. Revista do Instituto de Laticínios Cândido Tostes, Juiz de Fora, v.67, n.385, p.58-63, 2012.

HORST, J.A. Manual de Coleta de Amostras: Componentes e CCS. Curitiba: Programa de Análise de Rebanhos Leiteiros do Paraná APCBRH, 2010.

HORST, J.A. Manual de Operações de Campo. Curitiba: Programa de Análise de Rebanhos Leiteiros do Paraná - APCBRH, p.16, 2008.

INSTITUTO AGRONÔMICO DO ESTADO DO PARANÁ. Cartas climáticas do Estado do Paraná. Londrina, IAPAR, 2000. p.49 ilust. (IAPAR, Documento, 18).

$\begin{array}{llr}\text { INSTITUTO PARANAENSE } & \text { DE } \\ \text { DESENVOLVIMENTO ECONÔMICO E SOCIAL } \\ \text { (IPARDES). Leituras regionais: } & \text { Regiões } \\ \text { geográficas paranaenses: sumário. } & \text { Curitiba, } \\ 2004 . & & \end{array}$

INSTITUTO PARANAENSE DE DESENVOLVIMENTO ECONÔMICO E SOCIAL. Caracterização socioeconômica da atividade leiteira no Paraná. Curitiba, IPARDES: 2009.

INSTITUTO PARANAENSE DE $\begin{array}{lll}\text { DESENVOLVIMENTO ECONÔMICO E } & \text { E } \\ \text { SOCIAL. Caracterização da indústria de }\end{array}$ processamento e transformação do leite no Paraná. Curitiba, IPARDES: 2010
KOEHLER, J. C. Caracterização da bovinocultura de leite no Estado do Paraná. Curitiba: DERAL/SEAB, 2000. Disponível em: <http://www.pr.gov.br/seab/deral/cultura3.pdf>. Acesso em: 27/05/2015

LIMA, M.C.G.; SENA, M.J.; MOTA, R.A.; et al.; Contagem de células somáticas e análises físico-químicas e microbiológicas do leite cru tipo $\mathrm{C}$ produzido na região agreste do estado de Pernambuco. Arquivo do Instituto Biológico, v.73, n.1, p.89-95, 2006.

LOPES JÚNIOR, J. E. F.; LANGE, C. C.; BRITO, M. A. V. P. e; et al.; Relationship between total bacteria counts and somatic cell counts from mammary quarters infected by mastitis pathogens. Ciência Rural, Santa Maria, v.42, n.4, p.691-696, 2012.

LUZ, D.F.; BICALHO, F.A.; OLIVEIRA,; et al.; Avaliação microbiológica em leite pasteurizado e cru refrigerado de produtores da região do Alto Pantanal Sul-Mato-Grossense. Revista Agrarian, Dourados, v.4, n.14, p.367-374, 2011.

MARTINS, M.E.P.; NICOLAU, E.S.; MESQUITA, A.J.; et al.; Qualidade de leite cru produzido e armazenado em tanques de expansão no Estado de Goiás. Ciência Animal Brasileira, v.9, n.4, p.1152-1158, 2008.

MARTINS, M.E.P.; NICOLAU, E.S.; MESQUITA, A.J.; et al. Conservantes bronopol e azidiol: influência do binômio tempo/temperatura na contagem bacteriana total do leite cru. Ciência Animal Brasileira, v.10, n.2, p.627-633, 2009.

MEZZADRI, F. P. Análise da Conjuntura Agropecuária Ano 2013/14 - Leite DERAL/SEAB 2014. Disponível em: <http://www.agricultura.pr.gov.br/arquivos/File/d eral/Prognosticos/leite_2013_14.pdf>Acesso em 26/05/2015.

OSTRENSKY, A. Efeitos de ambientes sobre a contagem de células somáticas no leite de vacas da raça holandesa no Paraná. 1999. Curitiba, 114f. Dissertação (Mestrado em Ciências Veterinárias) - Curso de PósGraduação em Ciências Veterinárias, Universidade Federal do Paraná.

PAULA, M.C.; RIBAS, N.P.; MONARDES, H.G.; et al. Contagem de Células Somáticas em Amostras de Leite. Revista Brasileira de Zootecnia, Viçosa, v.33, n.5, p.1303-1308, 2004.

REVELLI, G.R.; SBODIO, O.A.; TERCERO, E.J. Recuento de bacterias totales en leche cruda de tambos que caracterizan la zona noroeste de Santa Fe y sur de Santiago del Estero. Revista Argentina de Microbiología. Beunos Aires, v.36, n.3, p.145-149, 2004. 
REVELLI, G.R.; SBODIO, O.A.; TERCERO, E.J. Estudio y evolución de la calidad de leche cruda en tambos de la zona noroeste de Santa Fe y sur de Santiago del Estero, Argentina. RIA Revista de Investigaciones Agropecuarias, Instituto Nacional de Tecnología Agropecuaria Argentina, v.37, n.2, p.128-139, 2011.

SANTOS, M.V.; FONSECA, L.F.L. 2006. Estratégias para Controle de Mastite e Melhoria da Qualidade do Leite. 1.ed. Barueri: Editora Manole, p.314.

SCHAIK, G.V.; GREEN, L.E.; GUZMÁN, D.; et al. Risk factors for bulk milk somatic cell counts and total bacterial counts in smallholder dairy farms in the 10th region of Chile. Preventive Veterinary Medicine Journal, v.67, n.1, p.1-17, 2005.

SHOOK, G.E. Aproaches to summarizing somatic cell count which improve interpretability. In: NATIONAL MASTITIS COUNCIL ANNUAL MEETING, 21, 1982, Pennsylvania. Proceedings... Madison: National Mastitis Council, 1982, p.150-166.

SILVA, A.C.L. da.; Como produzir leite com baixa contagem bacteriana. Cartilha leite de qualidade, Clínica do Leite-ESALQ-USP, edição. v.8, p.4, 2014.

SUHREN, G.; WALTE, H.G. First experiences with automatic flow cytometric determination of total bacterial count in raw milk. Bulletin of the international Dairy Federation (IDF), n.358, p.3648, 2000.

TAKAHASHI, F. $\mathrm{H}$. et al. Variação e monitoramento da qualidade do leite através do controle estatístico de processos. Ciência Animal Brasileira, Goiânia, v.13, n.1, p.99-107, 2012.

VALLIN, V.M.; BELOTI, V.; BATTAGLINI, A.P.P.; et al.; Melhoria da qualidade do leite a partir da implantação de boas práticas de higiene na ordenha em 19 municípios da região central do Paraná. Semina: Ciências Agrárias, v.30, n.1, p.181-188, 2009. 